\title{
Publisher Correction to: "I've Always Wanted a Gay Family Member!": Straight Ally Girls and Gender Inequality in a High School Gay-Straight Alliance
}

\section{Amie Levesque ${ }^{1}$}

Published online: 6 March 2019

(C) Springer Science+Business Media, LLC, part of Springer Nature 2019

\section{Publisher Correction to: Qualitative Sociology https://doi.org/10.1007/s11133-019-9411-9}

The original version of this article contained several mistakes.

Due to technical problems at the typesetter, author's last edits were not carried out. The publisher apologizes for these errors.

The corrections are enumerated as follows:

- the phrase “.... responses to Kate's, Stella's, and Johnny's experiences ....” should read as “.... responses to Kate's, Yvonne's, and Johnny's experiences ..."

- the phrase "Stella and Johnny were two self-identified ...." should read as "Yvonne and Johnny were two self-identified ...."

- the phrase "... according to Dorian, treated Dorian ... " should read as "... according to Dorian, treated her ..."

- the phrase "... popularly assumed at Park, generally — as I illustrate in more detail belowthat boys at Park High who..." should read as "popularly assumed at Park — as I illustrate in more detail below - that boys who"

- the phrase “... 16-year-old girl, rejected the GSA ..." should read as “... 16-year-old queeridentifying girl, rejected the GSA ..."

- the phrase "Taylor, a lesbian, acknowledged the ..." should read as "Taylor, a bisexual girl, acknowledged the ..."

The online version of the original article can be found at https://oi.org/10.1007/s11133-019-9411-9

Amie Levesque

amie.levesque@du.edu

1 University of Denver, Department of Sociology and Criminology, 2000 E. Asbury Ave, Denver, CO 80208, USA 
- the word "person" from the phrase "token, I guess, gay person." should be normal text only

- “... effeminate gay boys and find ..." to "... feminine boys and find ..."

- "... but in the club, straight ..." to "... but in the Park GSA, straight ..."

- "... called a unisex bathroom." to "... called a unisex bathroom in the nurse's office."

- "... gay-identifying peers in the GSA." to "... gay-identifying male peers in the GSA."

- "... majority of girls at Park who ..." to "... majority of straight girls at Park who ..."

- In the Acknowledgement, it should be changed as " This article has benefited greatly from the kindness of Tristan Bridges, Hava Gordon, Jennifer Reich, Alan Klein, Lisa Pasko, Alison Walton, and the anonymous reviewers who offered constructive feedback on this article. Please accept my gratitude for your valuable time and advice."

The original version has been corrected.

Publisher's Note Springer Nature remains neutral with regard to jurisdictional claims in published maps and institutional affiliations. 